\title{
CORRESPONDENCE
}

We welcome letters to the Editor concerning articles which have recently been published. Such letters will be subject to the usual stages of selection and editing; where appropriate the authors of the original article will be offered the opportunity to reply.

Letters should normally be under $\mathbf{5 0 0}$ words in length, double-spaced throughout, signed by all authors and fully referenced. The edited version will be returned for approval before publication.

\section{FAILURE OF CEMENTLESS HIP REPLACEMENTS}

Sir,

We disagree with the conclusions reached by $\mathrm{Kim}$ and $\mathrm{Kim}$ in their paper entitled 'Results of the Harris-Galante cementless hip prosthesis' in the January 1992 issue (1992; 74-B:83-7). Their results are at complete variance with those in our larger series of 201 primary Harris-Galante total hip arthroplasties in 180 patients. The operations were performed between November 1985 and December 1991 at Queen Mary's University Hospital and the Whittington University Hospital, London. We dispute the results stated in the paper on the following grounds:

1) The patient selection was poor with regard to age and aetiology. $\mathrm{Kim}$ and $\mathrm{Kim}$ state the age range of their patients to have been 24 to 86 years, but uncemented hip arthroplasties are generally reserved for the younger patient whose medullary canal is not excessively wide; in these patients partial weight-bearing is usually easier after operation.

In their series, $24 \%$ of the hips were replaced for femoral neck fracture with only $16 \%$ of the patients suffering from osteoarthritis. It is most unusual to include so many femoral neck fractures in a series to assess an uncemented total hip arthroplasty. In our series $73 \%$ of patients underwent their hip arthroplasty for osteoarthritis.

2) The incidence of thigh pain quoted in the paper was $50 \%$. In our series it was $2 \%$. The paper does not state in detail whether it was the older group of patients that went on to fail and have thigh pain. This very high incidence may be related to the poor patient selection mentioned above.

3) Their reported revision rate was very high for a shortterm series: we have had only one hip revision to date. Their high rate is probably also related to poor patient selection.

4) They quote a pre-operative Harris hip score between 9.4 and 81 . A score of 81 would normally preclude a patient from undergoing a total hip replacement. Our pre-operative Harris hip score was 37 (15 to 57) and at two-year followup was 91 ( 80 to 97 ). It would be interesting to know how a pre-operative score was obtained from the $24 \%$ of patients with femoral neck fractures undergoing this operation.

5) $\mathrm{Kim}$ and $\mathrm{Kim}$ do not state the period during which the study was carried out to enable an accurate charting of any changes in the design of the prosthesis to be made. An alteration was made to the femoral component 42 months ago (personal communication, Zimmer Ltd, Swindon, England): an extraction hole was added to the prosthesis as is shown in Kim and Kim's Figure 1. It is therefore

C) 1992 British Editorial Society of Bone and Joint Surgery $0301-620 X / 92 / 6500 \$ 2.00$

J Bone Joint Surg [ Br] 1992; 74-B:932-5. evident that these radiographs were not from a patient who had an operation performed 60 to 66 months ago as claimed in this paper.

Our results to date are inconsistent with those published in this paper. We would urge consideration of the points made in our letter, particularly regarding the extraction hole in the femoral component, and suggest verification of the stated follow-up period.

\section{BHAMRA, ChM, FRCS \\ A. L. HULME, FRCS \\ Westminster Hospital \\ London.}

\section{P. A. N. HUTTON, FRCS}

B. G. ANDREWS, FRCS

Queen Mary's University Hospital (Roehampton) London.

W. F. G. MUIRHEAD-ALLWOOD, FRCS

Whittington University Hospital

London.

Kim Y-H, Kim VEM. Results of the Harris-Galante cementless hip prosthesis. J Bone Joint Surg [Br] 1992;74-B:83-7.

\section{Reply from the authors:}

Sir,

Thank you for the opportunity to comment on the letter from Bhamra et al. We would like to congratulate them on their excellent results with cementless Harris-Galante total hip replacements.

In our Korean series, the patients are very different from those in the West, particularly in respect of their age and diagnosis. The average age in our series was 52 years with $52 \%$ under 50 . In about 500 total hip arthroplasties performed by the senior author in Korea the average age was only 50 years. The diagnosis was avascular necrosis of the femoral head in $35 \%$, neglected femoral neck fracture in $22 \%$, osteoarthritis secondary to childhood pyogenic arthritis in $21 \%$ and primary osteoarthritis in only $7 \%$. Other causes were osteoarthritis secondary to childhood tuberculous arthritis and rheumatoid arthritis.

The reasons for using total hip arthroplasty in these relatively young patients were as follows:

1) Patients will not accept hip fusion because this prevents habitual sitting on the floor.

2) Patients want almost normal hip function because of self-consciousness concerning their appearance. They would suffer discrimination if they were disabled.

3) The most common diagnosis was avascular necrosis which usually involves both femoral heads.

The average age of our patients with femoral neck fracture was 65.6 years ( 56 to 86 ), and the average age of the patients who had thigh pain (including persistent and disabling thigh pain due to component loosening) was 38.3 years (28 to 51 ). We believe that the high incidence of 
thigh pain in this young patient group is related to their high level of activity.

The average age of the eight patients who had component loosening was 40.5 years ( 26 to 58 ) and the younger patients had a higher incidence of failure.

The patient with a pre-operative hip score of 81 points was a 26-year-old woman with osteoarthritis secondary to childhood pyogenic arthritis. She limped moderately badly because of a leg-length discrepancy, but had only slight pain in her hip. She requested a better appearance and hip function before she got married. This type of indication is fairly common in Korea.

Our patients with femoral neck fracture almost all had neglected injuries and were seen at three to five months, having been first treated by an acupuncturist or a bone setter, which is common in Korea. When they are referred late to an orthopaedic surgeon it is easily possible to obtain a pre-operative hip score.

The patient shown in Figure 1 was not included in the series, having been operated on in October 1988. The figure was included only for illustration purposes. We should have explained this in the caption which indicated that revision was performed at 27 months after operation much shorter than the 60 months in our series. We apologise and take full responsibility for the omission.

We hope that we have answered the questions raised by Bhamra et al and wish to thank them for their close and thoughtful consideration of our publication.

\section{Y-H. KIM, MD}

V. E. M. KIM, MD

5569 North County Road 29

Loveland

Colorado, USA.

\section{RESECTION OF CALCANEAL PROMINENCE}

Sir,

We have read with interest the brief report in the March 1992 issue on 'Prominence of the calcaneus' by $\mathbf{H}$. $\mathbf{M}$. Huber (1992;74-B:315-6). The author does not mention, however, that his material has already been published in Italian and in German. These articles were co-authored by Dr M. Waldis.

We would also like to make clear that the Department of Orthopaedics at the University of Zürich is responsible for the 594 patients treated between 1946 and 1984 who were reported in the former articles.

We do not feel that the editorial board can be blamed for this dual publication, but we would, however, be grateful for the correction of this misunderstanding.

A. SCHREIBER, MD

Orthopädische Universitätsklinik

Zürich

Switzerland.

Huber HM. Prominence of the calcaneus: late results of bone resection. J Bone Joint Surg [Br] 1992;74-B:315-6.

Huber M, Waldis MF. Haglund disease: analysis of poor results of surgical treatment. Chir Piede 1989;13:159-62.

Huber HM, Waldis M. Haglund's disease - surgical indication and a minor operation. Z Orthop 1989;127:286-90.

\section{Reply from the author:}

Sir,

Thank you for the opportunity to reply to Professor Schreiber's letter. I clearly stated in my brief report that all the patients were operated on and followed up at the Balgrist Hospital. The 120 patients reported were a selected subgroup of the 594 patients to whom he refers and who were indeed the subject of the previous reports. My selection was made on the basis of choosing patients with pre- and postoperative radiographs and complete follow-up.

Furthermore, the recommendations for exact pre-operative planning - the only aim of the brief report - were not mentioned in either previous paper and I believe that this is the first time that such a method of deciding the optimal amount of bone resection has been published. My report is not just a 're-hash' of a previous paper: it is different, and did not require reference to the previous studies.

I am sorry that Professor Schreiber did not come to the same conclusion, especially as I am indebted to him for so much of my experience.

H. HUBER, MD

Hôpital de la Ville

La Chaux-de-Fonds

Switzerland.

\section{SURVIVORSHIP ANALYSIS}

Sir,

May I add a comment to Lettin, Ware and Morris's excellent article in the September 1991 issue on 'Survivorship analysis and confidence intervals' (1991;73-B:729-31)?

What has not yet been stated in any survivorship analysis study is that as follow-up time increases and the older patients die, the mean age of the survivors at the time that they had their operation, is gradually reduced. Any really long-term survivorship analysis thus becomes a measure of outcome of the procedure as performed in younger and younger patients.

B. M. WROBLEWSKI, FRCS

Wrightington Hospital for Joint Disease

Wigan

Lancashire.

Lettin AWF, Ware HS, Morris RW. Survivorship analysis and confidence limits: an assessment with reference to the Stanmore total knee replacement. J Bone Joint Surg [Br] 1991:73-B 729-31.

\section{HYDROXYAPATITE COATING OF PROSTHESES}

Sir,

You recently published our paper entitled 'Hydroxyapatite coating of hip prostheses' in which we described the migration rate over the first two postoperative years of a femoral prosthesis proximally coated with hydroxyapatite $(1992 ; 74-$ B:518-22). When this paper was submitted for publication no histological material was available to us upon which a description of the response of the skeleton to the implant coating could be based.

Two prostheses have now become available for histological study. One was obtained six months postoperatively from a patient whose hip required revision for infection. The other was from a patient whose acetabulum required revision for malpositioning three months after implantation. Neither of these patients had been operated on at the Royal London Hospital and they were not included in our paper.

It is important to those interested in the migration of implants to be able to relate migration to the histological events taking place at the interface. I therefore now write to report that the histological appearances around the coating 